Article

\title{
Fabrication of a solid superacid with temperature-regulated silica-isolated biochar nanosheets
}

\author{
Zengtian Chen a,b, Yuxue Xiao a,b, Chao Zhang a,* , Zaihui Fu a,\# , Ting Huang a, Qingfeng Li a, \\ Yuanxiong Yao a, Shutao Xu b, Xiaoli Pan b, Wenhao Luo b, Changzhi Li b,c,\$ \\ a National \& Local Joint Engineering Laboratory for New Petro-chemical Materials and Fine Utilization of Resources and Key Laboratory of Chemical \\ Biology and Traditional Chinese Medicine Research (Ministry of Education), College of Chemistry and Chemical Engineering, Hunan Normal University, \\ Changsha 410081, Hunan, China \\ b Dalian Institute of Chemical Physics, Chinese Academy of Sciences, Dalian 116023, Liaoning, China \\ c Dalian National Laboratory for Clean Energy, Chinese Aacdemy of Sciences, Dalian 116023, Liaoning, China
}

\section{A R T I C L E I N F O}

\section{Article history:}

Received 26 October 2019

Accepted 23 Novebmer 2019

Published 5 April 2020

\section{Keywords:}

Biomass conversion

Bio-based sulfonic acid

Silica isolation

Solid superacid

Acid catalysis

\begin{abstract}
A B S T R A C T
This paper reports a new strategy for the structural reconstruction of biomass carbon sulfonic acid (BCSA) to its solid superacid counterpart. In this approach, a cheap layered biomass carbon (BC) source is chemically exfoliated by cetyltrimethyl ammonium bromide and then converted to silica-isolated carbon nanosheets (CNSs) by a series of conversion steps. The state of the silica-isolated CNSs and the stacking density of their nanoparticles are regulated by the dehydration temperature. Only the highly isolated and non-crosslinked CNSs with loose particle stacking structures obtained upon dehydration at $250^{\circ} \mathrm{C}$ can be turned into superacid sites (with stronger acidity than that of $100 \% \mathrm{H}_{2} \mathrm{SO}_{4}$ ) after sulfonation. This is accompanied by the creation of abundant hierarchical slit pores with high external surface area, mainly driven by the strong hydrogen bonding interactions between the introduced sulfonic acid groups. In typical acid-catalyzed esterification, etherification, and hydrolysis reactions, the newly formed superacid exhibits superior catalytic activity and stability compared to those of common BCSA and commercial Amberlyst-15 catalysts, owing to its good structural stability, highly exposed stable superacidic sites, and abundance of mesoporous/macroporous channels with excellent mass transfer rate. This groundbreaking work not only provides a novel strategy for fabricating bio-based solid superacids, but also overcomes the drawbacks of BCSA, i.e., unsatisfactory structural stability, acidity, and porosity.
\end{abstract}

(C) 2020, Dalian Institute of Chemical Physics, Chinese Academy of Sciences. Published by Elsevier B.V. All rights reserved.

\section{Introduction}

Acid catalysis is one of the key strategies for the production of industrially important chemicals [1]. Solid acids are particu- larly attractive due to their easy separation, reductive corrosion, good recyclability, and green chemical processes [2-12]. Since their discovery in 2005, biomass carbon-derived solid sulfonic acids (BCSAs) have attracted worldwide attention as

\footnotetext{
* Corresponding author. E-mail: chaozhang2006@126.com

\# Corresponding author. E-mail: fzhhnnu@126.com

\$Corresponding author. E-mail: licz@dicp.ac.cn

We acknowledge the financial support for this work by the National Natural Science Foundation of China (21690080, 21676079, 21546010, 21690083, 21878288), the Strategic Priority Research Program of Chinese Academy of Sciences (XDB17020100), the Natural Science Foundation of Hunan Province (2018JJ3335), the Innovation Platform Open Fund of Hunan College (18K016), and DNL Cooperation Fund CAS (DNL180302). DOI: S1872-2067(19)63522-9 | http://www.sciencedirect.com/science/journal/18722067 | Chin. J. Catal., Vol. 41, No. 4, April 2020
} 
very promising solid acids [13-16], owing to their low cost, easy availability, and higher activity in some acid-catalyzed reactions compared to those of commercial sulfonated resins. However, a major challenge that limits their large-scale application is that the polycyclic aromatic carbon nanosheets (CNSs) composing the compact laminated structure of BCSAs suffer from partial leaching/dissolution in many condensed phases including water, and are unlikely to exhibit satisfactory long-term performances. Moreover, common BCSAs have some other intrinsic shortcomings, including unsatisfactory mass transfer efficiency, relative weakness, instability, and low exposure of acid sites $[17,18]$.

Several effective methods, such as chemical grafting of functionalized ionic liquids [19] and thermal carbonization under catalytic activation [20-23], as well as hard [24,25] or soft [26-28] templates, have been developed to overcome the above issues. In addition, some elegant methods have also been developed, mainly focused on increasing the acid density and spatial proximity of the sulfonated polystyrene resin to enhance the strength of its sulfonic acids [29-31], as well as varying the crystallinity, topological structure, morphology, and chemical composition of the inorganic solid acids to adjust their acid strengths [32-35]. Current methods have led to great progress in improving the properties of solid acids. However, most of these methods are still strategically complex or poorly efficient, and thus achieve only limited improvements in structure, acidity, or porosity. Therefore, it is highly desirable to develop new strategies to prepare an efficient solid acid that can meet the following requirements [16,17,36-38]: i) cheap and easily available precursors, along with a simple/practical fabrication method to facilitate its potential application; ii) sufficiently strong acidity (e.g., higher than that of $100 \% \mathrm{H}_{2} \mathrm{SO}_{4}$ ) and maximum exposure of acid sites on the external surface; iii) sufficient structural stability with abundant hierarchical pores, resulting in excellent accessibility and reusability.

Herein, we report a new structural reconstruction (SR) strategy for fabricating silica-isolated biomass carbon sulfonic acids (SIBCSAs) by using bamboo powder from forestry waste and very cheap water glass as the main raw materials. In the SR strategy, the layered bamboo carbon source was chemically exfoliated by cetyltrimethylammonium bromide (CTMA) solu- tion to yield its individual carbon nanosheets (CNSs, representing the building units of biomass carbon, BC), highly isolated by CTMA. Then, this binary composition was further combined with an acidic silica sol to yield a ternary composition, which was in turn converted into silica-isolated CNSs (SIBCs) via dehydration at 250 or $350^{\circ} \mathrm{C}$ and removal of CTMA. Finally, the silica-isolated CNSs were transformed into their sulfonated carbon nanosheet derivatives (SCNSs, marked as SIBCSAs) using concentrated $\mathrm{H}_{2} \mathrm{SO}_{4}$ (see Scheme 1). The structural reconstruction of the BCSAs can thus be successfully achieved using this strategy. A series of characterizations confirmed that the newly synthesized SIBCSA- 1 material (obtained after dehydration at $250{ }^{\circ} \mathrm{C}$ ) exhibits the representative features of efficient solid acids discussed above, and thus shows excellent catalytic performances in acid-catalyzed esterification, etherification, and hydrolysis reactions.

\section{Experimental}

\subsection{General information and methods}

All reagents were of analytical grade. Concentrated sulfuric acid, sodium silicate $\left(\mathrm{Na}_{2} \mathrm{SiO}_{3} \cdot 9 \mathrm{H}_{2} \mathrm{O}\right)$, oxalic acid, phenol, ferric chloride, ammonium nitrate, concentrated hydrochloric acid, sodium hydroxide, hexadecyl trimethyl ammonium bromide (CTMA), adipic acid, isooctanol, isobutene, methanol, hydroxypropyl cellulose, and Amberlyst-15 reagents were purchased from Sinopharm Chemical Reagent Co., Ltd.

\subsection{Preparation of BC material}

According to our patented procedure (ZL 201710129798.3), the bamboo carbon material was prepared by hydrothermal carbonization of bamboo powder. In detail, bamboo powder ( 6 g, main elemental composition listed in Table S1), ferric chloride (3.6 g), phenol (1.2 g), and $0.1 \mathrm{~mL}$ concentrated $\mathrm{HCl}$ were added to $10 \mathrm{~mL}$ of deionized water and then placed in a stainless steel $(100 \mathrm{~mL})$ reactor. Afterward, the stainless steel reactor was heated to $180^{\circ} \mathrm{C}$ and kept at that temperature for $9 \mathrm{~h}$. After carbonization, the reactor was cooled to room temperature in air and biochar was collected along with the liquid

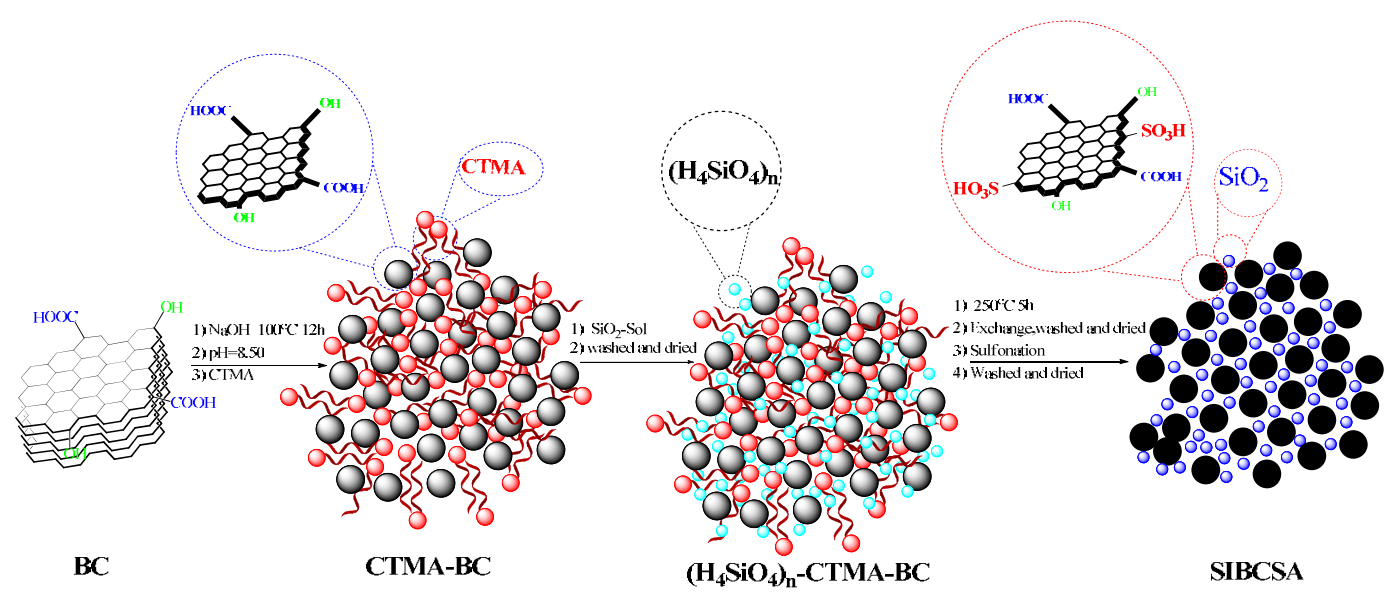

Scheme 1. Synthetic strategy for preparing silica-isolated biochar sulfonic acid (SIBCSA) via structural reconstruction. 
products. The obtained mixture was centrifuged and washed several times with distilled water, followed by drying at $60{ }^{\circ} \mathrm{C}$ in vacuum overnight to obtain black solid BC.

\subsection{Synthesis of acidic silica sol}

A $0.5 \mathrm{~mol} / \mathrm{L}$ acidic silica sol ( $\mathrm{pH}$ 3.5-4.0) was synthesized by adding $12 \mathrm{~mL}$ of $1 \mathrm{~mol} / \mathrm{L} \mathrm{Na}_{2} \mathrm{SiO}_{3}$ solution to $10 \mathrm{~mL}$ of $2 \mathrm{~mol} / \mathrm{L}$ oxalic acid solution dropwise, at $35{ }^{\circ} \mathrm{C}$, and with magnetic stirring. The particle size distribution of the $0.5 \mathrm{~mol} / \mathrm{L}$ silica sol was measured by a Nano ZS90 dynamic light scattering instrument with a HeNe laser $(\lambda=633 \mathrm{~nm})$. The light source (75 $\mathrm{mW}$ ) and the obtained results are shown in Fig. S1. The average particle size measured for the $0.5 \mathrm{~mol} / \mathrm{L}$ silica sol was about 17 nm.

\subsection{Synthesis of conventional biomass carbon sulfonic acid}

The BC material ( $3 \mathrm{~g}$ ) was sulfonated with $30 \mathrm{~mL}$ concentrated $\mathrm{H}_{2} \mathrm{SO}_{4}$ at $100{ }^{\circ} \mathrm{C}$ for $3 \mathrm{~h}$ (solid/liquid = 1:10 g:mL). After reaction, the sulfonated precipitate was filtered, repeatedly washed with distilled water until free from $\mathrm{SO}_{4}{ }^{2-}$ ions (as detected by $\mathrm{Ba}^{2+}$ ions), and dried at $60{ }^{\circ} \mathrm{C}$ in vacuum overnight, yielding BCSA. The contents of $\mathrm{OH}, \mathrm{COOH}$, and $\mathrm{SO}_{3} \mathrm{H}$ groups in BCSA were measured via chemical titration [39].

\subsection{Synthesis of silica-isolated BCSA}

First, the $\mathrm{BC}$ material (2 g) was treated with $\mathrm{NaOH}$ (1.2 g) in $12 \mathrm{~mL}$ distilled water; the treatment was carried out in a three-necked flask at $100{ }^{\circ} \mathrm{C}$ for $12 \mathrm{~h}$. After treatment, the mixture was cooled to $60{ }^{\circ} \mathrm{C}$ and its $\mathrm{pH}$ value was adjusted to 8.5 with $6 \mathrm{~mol} / \mathrm{L} \mathrm{HCl}$. Afterward, the reaction mixture was treated with CTMA ( $1.38 \mathrm{~g}$ ) at $60^{\circ} \mathrm{C}$ for $6 \mathrm{~h}$ with vigorous stirring. After treatment, the precipitate was filtered, washed three times with distilled water, and dried in vacuum at $60^{\circ} \mathrm{C}$ overnight to yield $3.26 \mathrm{~g}$ of a binary mixture denoted as CTMA-BC.

Then, $2 \mathrm{~g}$ CTMA-BC and $10 \mathrm{~mL}$ distilled water were mixed at $50{ }^{\circ} \mathrm{C}$ for $0.5 \mathrm{~h}$ in a three-necked flask with vigorous stirring. A $22 \mathrm{~mL}$ aliquot of the $0.5 \mathrm{~mol} / \mathrm{L}$ acidic silica sol was slowly added dropwise to the above mixture. After reacting at $50{ }^{\circ} \mathrm{C}$ for 3 $\mathrm{h}$, the resulting precipitate was filtered, washed three times with distilled water, and dried under vacuum at $60{ }^{\circ} \mathrm{C}$ overnight, to yield $2.90 \mathrm{~g}$ of a ternary mixture denoted as $\left(\mathrm{H}_{4} \mathrm{SiO}_{4}\right)_{n}$-CTMA-BC. In the following step, the above mixed solid was heated to 250 or $350{ }^{\circ} \mathrm{C}$ in a tube furnace, through temperature programming with a heating rate of $1{ }^{\circ} \mathrm{C} / \mathrm{min}$ under $\mathrm{N}_{2}$ atmosphere, followed by dehydration for $5 \mathrm{~h}$ at the selected temperature. After cooling the furnace to $25^{\circ} \mathrm{C}$, the dehydrated black solid was treated with a $3 \mathrm{~mol} / \mathrm{L}$ aqueous solution of ammonium nitrate (solid/liquid = 1:30 g:mL) under magnetic stirring at $100{ }^{\circ} \mathrm{C}$ for $3 \mathrm{~h}$. The precipitate was filtered, washed three times with distilled water, and dried under vacuum at $60^{\circ} \mathrm{C}$ overnight, to yield $1.14-1.00 \mathrm{~g}$ of silica-isolated BC solid; the SIBC samples dehydrated at 250 at $350{ }^{\circ} \mathrm{C}$ were labeled SIBC-1 and SIBC-2, respectively. Finally, the SIBC solid was converted to its sulfonated derivative through the same sulfonation conditions applied in the synthesis of BCSA (the corresponding samples were denoted as SIBCSA-1 and SIBCSA-2). The $\mathrm{SiO}_{2}$ content of the materials was measured by a high-temperature combustion treatment at $950{ }^{\circ} \mathrm{C}$ for $9 \mathrm{~h}$ in air. The $\mathrm{OH}, \mathrm{COOH}$, and $\mathrm{SO}_{3} \mathrm{H}$ densities of the materials were measured via chemical titration [39].

\subsection{Characterizations}

Fourier transform infrared (FT-IR) spectra of the samples in the $400-4000 \mathrm{~cm}^{-1}$ region were recorded on a Nicolet Avatar 370 spectrometer using $\mathrm{KBr}$ pellets. Transmission electron microscopy (TEM) and scanning transmission electron microscopy (STEM) images were obtained on a JEM-2100F instrument equipped with a high-angle annular dark field (HAADF) detector and an Oxford energy-dispersive X-ray spectroscopy (EDS) detector under an accelerating voltage of 220 $\mathrm{kV} .{ }^{13} \mathrm{C},{ }^{29} \mathrm{Si}$, and trimethylphosphine oxide (TMPO)-adsorbed ${ }^{31} \mathrm{P}$ magic-angle spinning (MAS) solid NMR spectra (Bruker AVANCE $\amalg 500 \mathrm{~Hz}$ ) were measured on a Varian Infinitypuls-400 spectrometer equipped with a $4 \mathrm{~mm}$ double-resonance MAS probe at a $10 \mathrm{kHz}$ spinning rate. The corresponding measurement conditions and procedures are described in our recent publication [40]. The Brunauer-Emmett-Teller (BET) specific surface area, pore volume, and Barrett-Joyner-Halenda (BJH) pore size distribution of the samples were measured on a Micromeritics ASAP 2400 low-temperature $\mathrm{N}_{2}$ adsorption apparatus after evacuation of the sample at $150^{\circ} \mathrm{C}$. Thermogravimetric analysis (TGA) of the samples was performed on a NETZSCH-STA 409PC instrument at a $20^{\circ} \mathrm{C} \cdot \mathrm{min}^{-1}$ heating rate under $\mathrm{N}_{2}$ flow $(10 \mathrm{~mL} / \mathrm{min})$.

\subsection{Detailed procedures of acid-catalyzed reactions}

The etherification of isobutene to methyl tert-butyl ether (MTBE) in methanol, the esterification of adipic acid to diisooctyl adipate (DOA) with isooctanol, and the hydrolysis of hydroxypropyl cellulose to reducing sugars (RSs) were employed to evaluate the catalytic performances of the present solid acids. The corresponding procedures are described in the following sections.

\subsubsection{Etherification reaction procedure}

The liquid-phase etherification reaction for the synthesis of MTBE was carried out in a stainless steel autoclave (YZ-MR-100 ML). In a typical experiment, 2.7 mol methanol and $0.4 \mathrm{~g}$ catalyst were added to the autoclave simultaneously. Then, the sealed reactor was pressurized to $1.5 \mathrm{MPa}$ with $\mathrm{N}_{2}$ and $0.18 \mathrm{~mol}$ isobutene was introduced in the pressurized reactor. The reaction mixture was heated to $65^{\circ} \mathrm{C}$ and kept at this temperature for $2 \mathrm{~h}$, with vigorous magnetic stirring. After reaction, the mixture was separated by centrifugation and the etherified MTBE product in the filtrate was analyzed on a Shimadzu GC-2010Plus instrument equipped with an SE-54 quartz capillary column $(30 \mathrm{~m} \times 0.32 \mathrm{~mm} \times 0.25 \mu \mathrm{m})$ and a flame ionization detector (FID), using cyclopentanone as an internal standard. The temperatures of both injector and detector were 
Table 1

Silica content, acid group density, and porosity parameters of investigated samples.

\begin{tabular}{|c|c|c|c|c|c|c|c|c|}
\hline \multirow{2}{*}{ Sample } & \multirow{2}{*}{$\begin{array}{c}\mathrm{SiO}_{2} \\
\text { (wt.\%) }\end{array}$} & \multicolumn{3}{|c|}{ Acid group density (mmol/g) } & \multicolumn{4}{|c|}{ Porosity parameters } \\
\hline & & $\mathrm{COOH}$ & $\mathrm{OH}$ & $\mathrm{SO}_{3} \mathrm{H}$ & $S_{\text {BET }}\left(\mathrm{m}^{2} / \mathrm{g}\right)$ & $S_{\text {t-plot }}{ }^{\mathrm{a}}\left(\mathrm{m}^{2} / \mathrm{g}\right)$ & $P_{\mathrm{V}}\left(\mathrm{cm}^{3} / \mathrm{g}\right)$ & $D(\mathrm{~nm})$ \\
\hline$\overline{\mathrm{BC}}$ & 0.34 & 0.37 & 1.62 & - & - & - & - & - \\
\hline BCSA & 0.45 & 0.43 & 1.86 & 3.46 & - & - & - & - \\
\hline Amberlyst-15 & - & - & - & 5.00 & 42.5 & - & 0.40 & 28.8 \\
\hline SIBC-1 & 30.96 & 0.14 & 0.52 & - & $98\left(6^{b}\right)$ & 92 & 0.34 & 13.9 \\
\hline SIBCSA-1 & 32.11 & 0.70 & 0.95 & 1.57 & 218 & 211 & 0.38 & 6.5 \\
\hline SIBC-2 & 35.21 & 0.28 & 0.25 & - & $159\left(36^{b}\right)$ & 123 & 0.38 & 9.5 \\
\hline SIBCSA-2 & 36.06 & 0.18 & 0.76 & 1.19 & $285\left(136^{b}\right)$ & 149 & 0.50 & 4.4 \\
\hline
\end{tabular}

${ }^{a} t$-plot external surface areas. ${ }^{b}$ The values in brackets indicate the $t$-plot micropore surface areas.

set to $250{ }^{\circ} \mathrm{C}$, while the column temperature was increased from $35{ }^{\circ} \mathrm{C}$ (maintained for $4 \mathrm{~min}$ ) to $100{ }^{\circ} \mathrm{C}$ at $50{ }^{\circ} \mathrm{C} / \mathrm{min}$ and maintained for $3 \mathrm{~min}$ at $100{ }^{\circ} \mathrm{C}$. The separated catalyst was thoroughly washed with petroleum ether, dried under vacuum at $60^{\circ} \mathrm{C}$ overnight, and then reused in the next recycling run.

\subsubsection{Esterification reaction procedure}

In a typical procedure, $750 \mathrm{mmol}$ isooctanol, $300 \mathrm{mmol}$ adipic acid, and $0.5 \%$ catalyst (defined as $\mathrm{mmol} \mathrm{SO}_{3} \mathrm{H} / \mathrm{mmol}$ adipic acid $\times 100 \%$ ) were mixed in a three-necked glass reactor equipped with a water segregator and a condenser under magnetic stirring. The mixture was stirred at $125^{\circ} \mathrm{C}$ and a sample was collected every $10 \mathrm{~min}$. After reaction, the catalyst was filtered and the residual adipic acid in the filtrate was measured according to the Chinese standard GB/T1668-2008; the yield of DOA was then calculated based on the consumption of adipic acid. The used catalyst was thoroughly washed with ethanol and distilled water, dried under vacuum at $60^{\circ} \mathrm{C}$ overnight, and then reused in the next recycling run. The kinetic experiments illustrated in Fig. S2 were performed under the following conditions: $600 \mathrm{mmol}$ isooctanol, $150 \mathrm{mmol}$ adipic acid, and $0.2 \%$ catalyst at $125^{\circ} \mathrm{C}$ (or $115^{\circ} \mathrm{C}$ ), with sample collection every $10 \mathrm{~min}$.

\subsubsection{Hydrolysis reaction procedure}

All hydroxypropyl cellulose hydrolysis experiments were carried out in a stainless steel microautoclave (YZ-MR-100 ML). The detailed procedure is as follows: first, $0.4 \mathrm{~g}$ hydroxypropyl cellulose, $0.2 \mathrm{~g}$ catalyst, and $25 \mathrm{~mL}$ deionized water were simultaneously added to the autoclave, and the sealed reactor was maintained at $140{ }^{\circ} \mathrm{C}$ for $3 \mathrm{~h}$. After the autoclave was cooled down to room temperature, the reaction mixture was centrifuged to separate the solid catalyst. Thereafter, the yield of the liquid RS products was measured by the dinitrosalicylic acid (DNS) method.

To evaluate the activity of the catalysts in the three reactions discussed above, the turnover frequency (TOF) was estimated as the molar amount of converted substrate per mole of effective acid sites $\left(-\mathrm{SO}_{3} \mathrm{H}\right)$, per unit time $\left(\mathrm{min}^{-1}\right.$ or $\left.\mathrm{h}^{-1}\right)$.

\section{Results and discussion}

\subsection{Characterization}

Table 1 shows that the acidity of BCSA originates from its hydroxyl $(\mathrm{OH})$, carboxyl $(\mathrm{COOH})$, and sulfonic acid $\left(\mathrm{SO}_{3} \mathrm{H}\right)$ groups, whose contents are 1.86, 0.43 , and $3.46 \mathrm{mmol} / \mathrm{g}$, respectively. In addition, the material contains $0.45 \mathrm{wt} . \%$ silica originating from the raw bamboo material. Compared to BCSA, the acidic group content of the two SIBCSA materials decreases to some extent, owing to the dilution effect of the introduced silica. Notably, the BC, SIBC-1, and SIBC-2 precursors generally have lower silica, $\mathrm{COOH}$, and (especially) $\mathrm{OH}$ contents than their corresponding sulfonated materials (BCSA, SIBCSA-1, and SIBCSA-2), indicating that carbonization, carboxylation, and especially hydroxylation of these precursors occur simultaneously during sulfonation by dehydration and oxidation of $\mathrm{H}_{2} \mathrm{SO}_{4}$. Table 1 also shows that increasing the dehydration temperature of the SIBC precursor from 250 to $350{ }^{\circ} \mathrm{C}$ causes the silica content of its sulfonated SIBCSA counterpart to increase from $30.96 \mathrm{wt} . \%$ to $35.21 \mathrm{wt} . \%$ and the $\mathrm{SO}_{3} \mathrm{H}$ density to decrease from 1.57 to $1.19 \mathrm{mmol} / \mathrm{g}$. These changes can be attributed to an increase in the degree of carbonization.

The morphologies of SIBCSA- 1 and of some of its precursors were observed by TEM, and the obtained images are shown in Figure 1. The parent BC material (Fig. 1a) exhibits a large block-like shape and a compact layered structure characteristic in its side. In addition, small amounts of nanoparticles (with a diameter of $c a$. 5-8 $\mathrm{nm}$ ) form loose aggregates on the sample edge, likely implying that the layered BC material is formed through the compact aggregation of these nanoparticles via
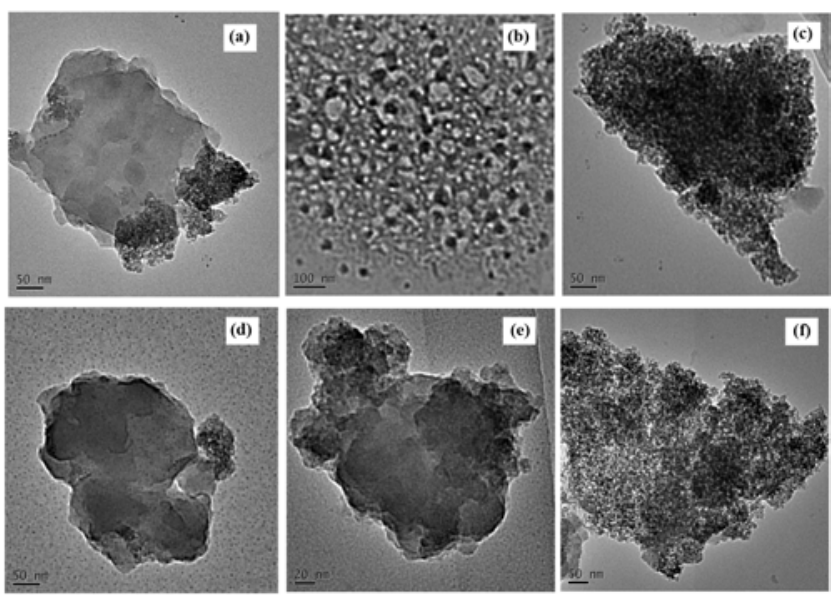

Fig. 1. TEM morphology of (a) BC, (b) CTMA-BC, (c) SIBC-1, (d) SIBC-2, (e) SIBCSA-1, and (f) $\mathrm{Na}^{+}$-exchanged SIBCSA-1 samples. 
strong hydrogen bonding (HB) interactions between their surface polar $\mathrm{OH}$ and $\mathrm{COOH}$ groups [29-31]. The TEM image of CTMA-BC in Fig. 1b shows that the sample is composed of fully dispersed nanoparticles of 10-50 nm size, likely reflecting the highly isolated state of the BC nanosheets exfoliated by CTMA. Such binary composition was treated with the acidic silica sol to yield its ternary counterpart, which further transforms into the SIBC- 1 sample after $250{ }^{\circ} \mathrm{C}$ dehydration and removal of CTMA. SIBC-1 exhibits disordered and loose aggregates of particles of about $12 \mathrm{~nm}$ size (Fig. 1c); these particles do not show significant difference in chromatic aberration, indicating that the majority of the CNS and silica components have been uniformly dispersed into each other. In sharp contrast, the control sample SIBC-2 obtained upon $350{ }^{\circ} \mathrm{C}$ dehydration displays a very similar layered structure to the parent $\mathrm{BC}$ material (Fig. 1d), suggesting that the high dehydration temperature likely drives the silica-isolated CNSs to reunite. After SIBC-1 is eventually converted to its sulfonated counterpart (SIBCSA-1) using $\mathrm{H}_{2} \mathrm{SO}_{4}$, the original loose aggregates turn into layered ones (Fig. $1 \mathrm{e})$, probably induced by the strong hydrogen bond interactions among the introduced sulfonic groups. This conclusion is supported by the observation that when the sulfonic protons of SIBCSA-1 are exchanged with an $\mathrm{NaCl}$ solution under ultrasonication, the obtained $\mathrm{SO}_{3} \mathrm{Na}$-exchanged sample (Fig. 1f) fully recovers its nanoparticle aggregate structure, similar to that of SIBC-1. In contrast, the layered morphology of BCSA hardly changes after being converted into the $\mathrm{SO}_{3} \mathrm{Na}$-exchanged sample (see Figs. S3a and S3b), indicating that, unlike SIBCSA-1, BCSA does not exhibit strong hydrogen bond interactions among the $\mathrm{SO}_{3} \mathrm{H}$ groups.

The combination of STEM and EDS techniques is a powerful tool for determining the composition and distribution of elements at the micro-interface of materials on a near-nanometer scale $[41,42]$, and is thus applied to study the present solid acids. Figures $2 a-2 c$ display overlaid elemental mappings of BCSA, SIBCSA-1, and SIBCSA-2 (the individual element mappings, corresponding HAADF-STEM images, and EDS spectra are also shown in Fig. 2). The $\mathrm{C}, \mathrm{S}$, and $\mathrm{O}$ atoms exhibit a fairly uniform distribution in the overlaid elemental mapping of BCSA (Fig. 2a), reflecting the homogeneous distribution of the $\mathrm{COOH}, \mathrm{OH}$, and $\mathrm{SO}_{3} \mathrm{H}$ groups. The content of $\mathrm{SO}_{3} \mathrm{H}$ groups in BCSA, calculated from the EDS composition analysis (Fig. 2d), is ca. $1.36 \mathrm{mmol} / \mathrm{g}$, which accounts for only $39 \%$ of the amount measured by chemical analysis ( $3.46 \mathrm{mmol} / \mathrm{g})$. This indicates that the $\mathrm{SO}_{3} \mathrm{H}$ groups of BCSA have a low degree of exposure, due to their incorporation in the dense layers of BCSA. The distributions of $\mathrm{C}$ and $\mathrm{Si}$ atoms are fairly uniform in most areas of the overlaid elemental mapping of SIBCSA-1, but significantly inhomogeneous in the bottom (marked as 1) and especially left (marked as 2) regions of Fig. 2b, which present carbon enrichment and silicon depletion. This indicates that SIBCSA-1 has at least two kinds of sulfonated carbon nanosheets found in either high or low silica-isolated states, with the high isolated state being clearly predominant. Based on EDS elemental analysis, the content of surface $\mathrm{SO}_{3} \mathrm{H}$ groups is estimated to be 1.15 mmol/g (Fig. 2e), which accounts for $c a .73 \%$ of the total amount of $\mathrm{SO}_{3} \mathrm{H}$ groups $(1.57 \mathrm{mmol} / \mathrm{g}$ ) measured by chemical analysis. This suggests that silica isolation can significantly improve the exposure of the $\mathrm{SO}_{3} \mathrm{H}$ groups. Notably, the distributions of $\mathrm{C}$ and $\mathrm{Si}$ atoms are fairly inhomogeneous in most areas of the overlaid elemental mapping of SIBCSA-2, denoting carbon enrichment and silicon depletion features (Fig. 2c) that correspond to the high carbon (53.7\%) and low Si (15.9\%) contents observed in the EDS analysis (Fig. 2f). Moreover, the content of surface $\mathrm{SO}_{3} \mathrm{H}$ groups calculated from the EDS elemental analysis is $1.88 \mathrm{mmol} / \mathrm{g}$, which is significantly higher than the actual content $(1.19 \mathrm{mmol} / \mathrm{g})$ measured by chemical analysis. This indicates that thermal migration of the isolated CNSs to the silica surface can take place easily under deep dehydration conditions.

The thermal decomposition behavior of the three solid acids was investigated by the TGA technique, and the differential thermogravimetry (DTG) curves are shown in Fig. 3a (the corresponding TGA curves are shown in Fig. S4). The DTG curve of BCSA displays two main weight loss peaks in the $50-350{ }^{\circ} \mathrm{C}$ range. The first peak at $134{ }^{\circ} \mathrm{C}(9.4 \%$ weight loss in the DTG curve) can be assigned to evaporation of the adsorbed water molecules located between the inner layers of BCSA. Another strong peak at $258^{\circ} \mathrm{C}(23.7 \%$ weight loss $)$ can be attributed to the decomposition process of $\mathrm{SO}_{3} \mathrm{H}$ groups [19]. The two SIBCSA materials exhibit similar TGA/DTG thermal decomposition behaviors to those described above; however, the weight loss peak corresponding to adsorbed water is weaker and shifted to low temperatures in SIBCSA-1 (7.72\% weight loss at $122^{\circ} \mathrm{C}$ ) and especially SIBCSA-2 (4.94\% weight loss at $\left.106^{\circ} \mathrm{C}\right)$, indicating that the water adsorption capacity of these two materials is reduced, likely due to the low density of sulfonic acid groups. In addition, the deep dehydration process contributes to decrease the hydrophilicity of SIBCSA-2. Another weight loss peak corresponding to the $\mathrm{SO}_{3} \mathrm{H}$ groups in the DTG curve of SIBCSA-1 also becomes weaker and broader (with a weight loss of $c a .13 .11 \%$ ), and is shifted by $24{ }^{\circ} \mathrm{C}$ toward high temperatures. On the other hand, this peak appears at $254{ }^{\circ} \mathrm{C}$ with $c a$. $11.69 \%$ weight loss for SIBCSA-2, corresponding to a slight shift toward low temperatures compared to that of BCSA. In generally, the thermal stability and acidity of sulfonated materials can be improved by increasing the density and spatial proximity of their $\mathrm{SO}_{3} \mathrm{H}$ groups [29-31], and in particular by introducing halogen substituents on the polyaromatic ring [43-46]. This is mainly because the C-S bonds can be strengthened by increasing the delocalization of the negative charges of the sulfonate group toward the aromatic ring via the HB interactions of the $\mathrm{SO}_{3} \mathrm{H}$ groups [29-31] and the electron-withdrawing effect of the halogen substituent [43-46]. The enhanced thermal stability of SIBCSA-1 suggests the existence of strong $\mathrm{HB}$ interactions between its $\mathrm{SO}_{3} \mathrm{H}$ groups, probably created by the migration and rearrangement of its high silica-isolated CNSs with a loose stacking particle structure during sulfonation. However, BCSA and SIBCSA-2 lack these strong $\mathrm{HB}$ interactions between their $\mathrm{SO}_{3} \mathrm{H}$ groups, because both the BC and SIBC-2 precursors possess a densely layered structure that hinders the migration and rearrangement of their CNSs during sulfonation, in agreement with the above TEM results. 
The porosity largely determines the activity of a heterogeneous catalyst. The porosity of SIBCSA-1 and SIBCSA-2, as well as that of the SIBC- 1 and SIBC-2 precursors, was measured by low-temperature $\mathrm{N}_{2}$ adsorption-desorption experiments. Compared to the nonporous nature of BCSA [47], the $\mathrm{N}_{2}$ adsorption-desorption isotherms in Fig. 3b show that SIBCSA-1 presents typical type-IV isotherms with a hysteresis loop in the $P / P_{0}$ range of $0.6-0.95$, indicating characteristic interlayer slit-like pores [48]. The BJH pore distribution curve of SIBCSA-1 displayed in the inset of Fig. 3b shows a bimodal pore distribution, with most of the mesopores located in the 2-15 $\mathrm{nm}$ range and a certain amount of large pores with diameter greater than $100 \mathrm{~nm}$. Similar to SIBCSA-1, SIBCSA-2 also shows type-IV isotherms with a hysteresis loop in the $P / P_{0}$ range of $0.5-0.9$ (Fig. 3c); however, its bimodal $\mathrm{BJH}$ pore distribution is much less defined than that of SIBCSA-1. This indicates that mesopores
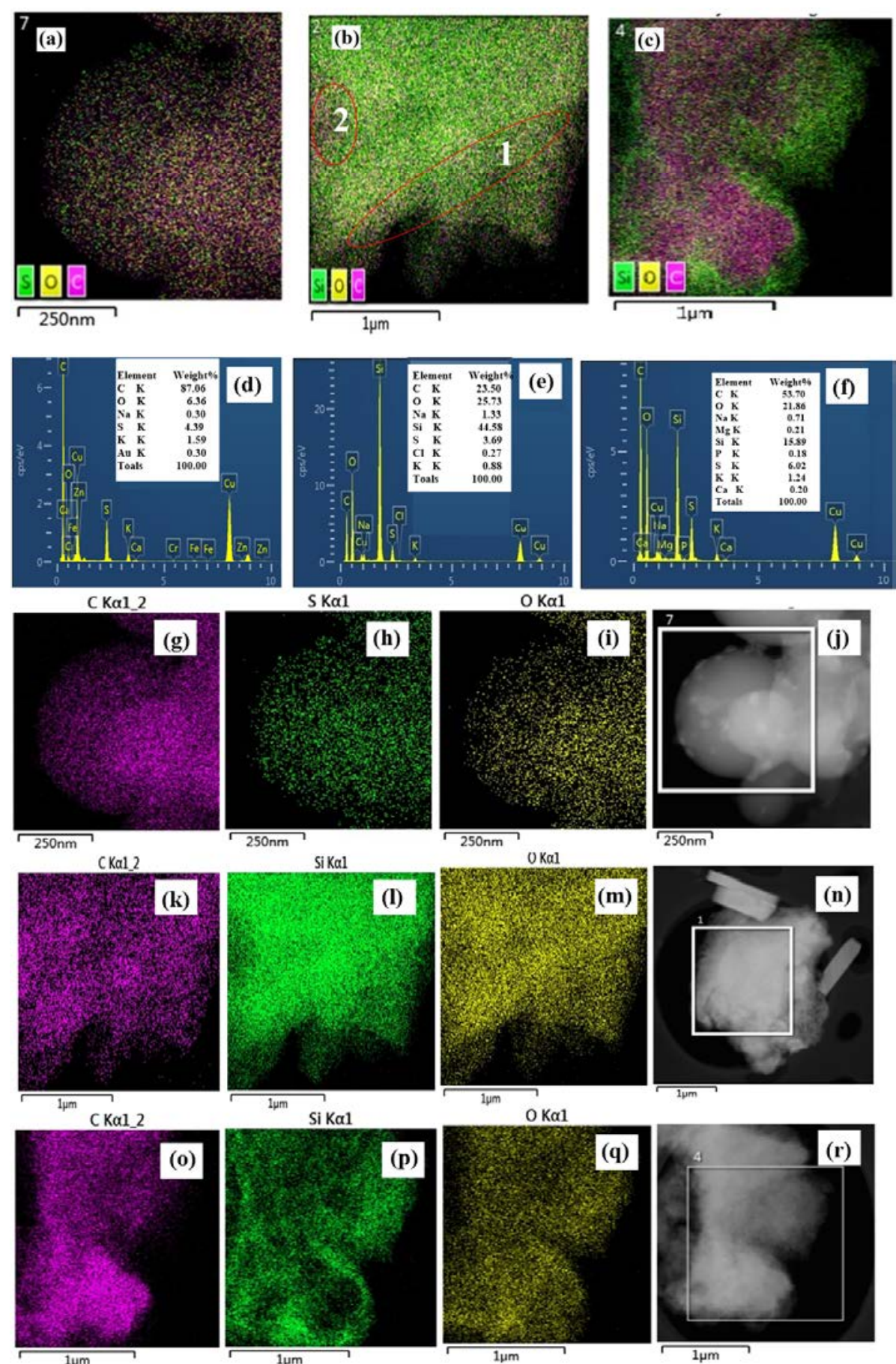

Fig. 2. Characterization of the catalysts. Overlaid elemental mappings of (a) BCSA, (b) SIBCSA-1, and (c) SIBCSA-2. EDS analysis of (d) BCSA, (e) SIBCSA-1, and (f) SIBCSA-2. Individual elemental mappings of (g) C, (h) Si, and (i) 0, along with (j) the corresponding STEM-HAADF image of BCSA. Individual elemental mappings of $(\mathrm{k}) \mathrm{C}$, (l) Si, and (m) O, along with (n) the corresponding STEM-HAADF image of SIBCSA-1. Individual elemental mappings of (o) C, (p) Si, and (q) O, along with (r) the corresponding STEM-HAADF image of SIBCSA-2. 

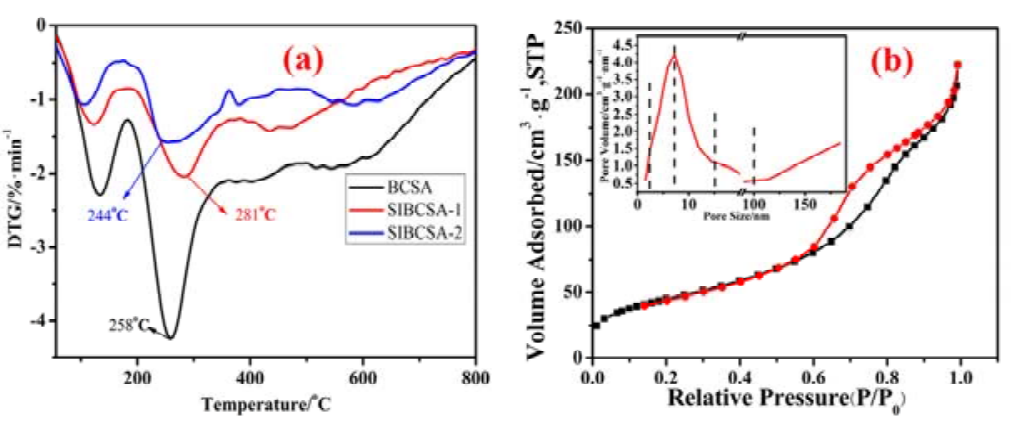

(d)
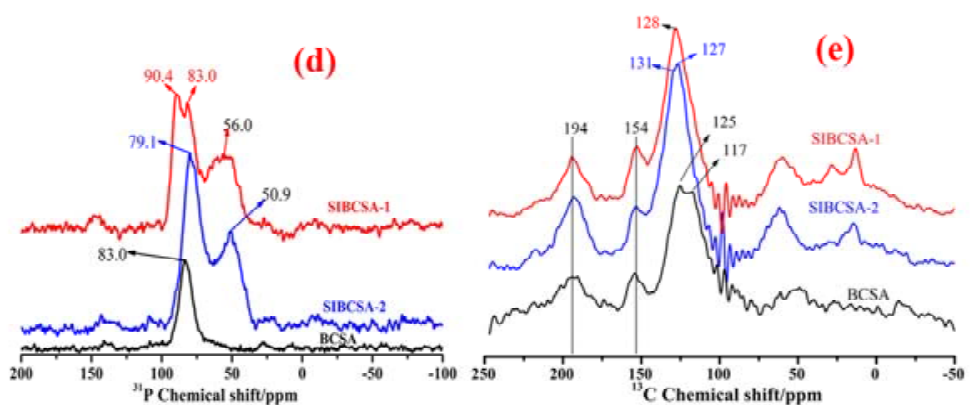

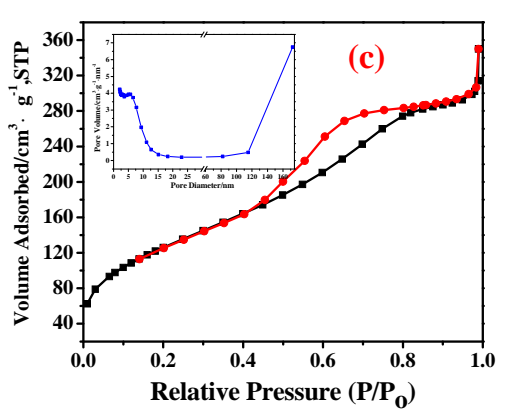

$\mathrm{Q}_{3} \mathrm{Q}_{4}$

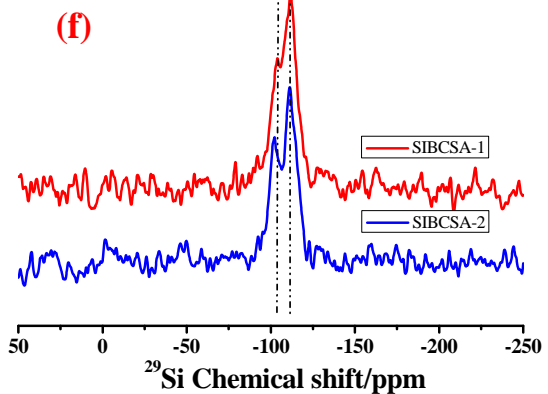

Fig. 3. (a) DTG curves of BCSA, SIBCSA-1, and SIBCSA-2. Adsorption-desorption isotherms and BJH pore distribution of SIBCSA-1 (b) and SIBCSA-2 (c) (d) ${ }^{31} \mathrm{P},(\mathrm{e}){ }^{13} \mathrm{C}$, and (f) ${ }^{29} \mathrm{Si}$ solid-state MAS NMR spectra of BCSA, SIBCSA-1, and SIBCSA-2.

are present in significantly lower amounts than macropores in the SIBCSA-2 structure, which also contains an appreciable amount of micropores smaller than $2 \mathrm{~nm}$ (see the BJH curve in the inset of Fig. 3c). Figure S5 shows that SIBC-1 and SIBC-2 exhibit similar $\mathrm{N}_{2}$ adsorption-desorption isotherms and $\mathrm{BJH}$ pore distributions to the sulfonated samples. Table 1 shows that the BET and t-plot external surface areas $\left(S_{\text {BET }}\right.$ and $S_{\text {t-plot, }}$ $\left.\mathrm{m}^{2} / \mathrm{g}\right)$, average pore size $(D, \mathrm{~nm})$, and porous volume $\left(V_{\mathrm{p}}\right.$, $\mathrm{cm}^{3} / \mathrm{g}$ ) of SIBC-1 are 98, 92, 13.9, and 0.34, respectively. Compared to SIBC-1, the $S_{\text {BET, }} S_{\mathrm{t} \text {-plot, }}$ and $V_{\mathrm{p}}$ values of SIBC-2 increase to some extent, but its $D$ value markedly decreases to $9.5 \mathrm{~nm}$, along with an increase in its microporous surface area (36 $\mathrm{m}^{2} / \mathrm{g}$ ). These results indicate that increasing the dehydration temperature promotes the formation of the dense stacking pores and the partial cross-linking pores of the silica-isolated CNS nanoparticles, in agreement with the above TEM results. After sulfonation of the two precursors, their porosity is significantly improved, leading to marked increases in the $V_{\mathrm{p}}$ and especially $S_{\mathrm{BET}}$ values, accompanied by a significant decrease in the $D$ values, indicating that the sulfonation process can trigger aggregation of the silica-isolated CNS particles to generate more abundant and smaller slit-like interlayer pores. Notably, SIBCSA-1 exhibits a clearly superior pore distribution compared to that of its precursor, and is entirely composed of slit-like pores with a high external surface area of $211 \mathrm{~m}^{2} / \mathrm{g}$, suggesting that the creation of interlayer slit-like pores is mainly driven by the strong hydrogen bonding interactions between the introduced sulfonic acid groups. On the other hand, SIBCSA-2 possesses a much larger microporous surface area of $135 \mathrm{~m}^{2} / \mathrm{g}$, which accounts for almost half of the total BET surface area of $285 \mathrm{~m}^{2} / \mathrm{g}$. This indicates that the cross-linking between the CNSs that migrate to silica surface can be significantly accelerated under the action of $\mathrm{H}_{2} \mathrm{SO}_{4}$, thus forming abundant micropores, which are the main contributors to the significantly enhanced porosity of SIBCSA-2.

TMPO-adsorbed 31P MAS NMR spectroscopy was used to evaluate the acidity of the three solid acids. As shown in Fig. 3d, BCSA only exhibits one ${ }^{31} \mathrm{P}$ NMR peak at $83.0 \mathrm{ppm}$ attributed to the $\mathrm{SO}_{3} \mathrm{H}$ groups [49], and no ${ }^{31} \mathrm{P}$ NMR signal for the weak acidic groups appears in its spectrum. This may imply that these weak acidic groups are not accessible to the probing TMPO molecules, owing to an obstruction of their extended HB network. In contrast, SIBCSA-1 and SIBCSA-2 clearly display the 31P NMR peak corresponding to the weak acid sites at 54.4 and $50.9 \mathrm{ppm}$, which are shifted by about 6 and 2 ppm, respectively, to low field compared to the peak position reported in literature [40]. This indicates that the accessibility and strength of the weak acid sites of SIBCSA-2 and especially SIBCSA-1 are improved, likely due to the breakage of the hydrogen bonding network upon silica isolation. In addition, SIBCSA-1 displays two ${ }^{31} \mathrm{P}$ NMR peaks in the $80-91$ ppm range, indicating the presence of two types of $\mathrm{SO}_{3} \mathrm{H}$ groups with different acidities. According to its peak area, the peak at $83.0 \mathrm{ppm}$ (similar to that of BCSA) accounts for about $42.5 \%$ of the total sulfonic acid content, which likely corresponds to the carbon-rich and silicon-depleted region in Fig. 2b. The other peak at 90.4 ppm is clearly shifted to low field, indicating the presence of superacid sites stronger than $100 \%$ sulfuric acid [50] in SIBCSA-1. The corresponding peak area accounts for $c a .57 .5 \%$ of the total peak area of the $\mathrm{SO}_{3} \mathrm{H}$ groups, which approximately matches the region with uniform silicon and carbon distribution in Fig. 2b. In contrast, SIBCSA-2 only exhibits a ${ }^{31}$ P NMR peak at 79.1 ppm attributable to the $\mathrm{SO}_{3} \mathrm{H}$ groups, which corresponds to the carbon-rich and silicon-depleted features of its elemental map- 
ping, indicating that this material has acidity similar to that of BCSA. These findings further confirm that only those SCNSs completely isolated by silica can exhibit superacidity through the strong $\mathrm{HB}$ interactions developed via the $\mathrm{SO}_{3} \mathrm{H}$ groups, in line with the above TEM and TGA results. The solid-state ${ }^{13} \mathrm{C}$ and ${ }^{29} \mathrm{Si}$ MAS NMR spectra provide insight into the surface species of BCSA, SIBCSA-1, and SIBCSA-2. As shown in Figure 3e, the ${ }^{13} \mathrm{C}$ MAS NMR spectrum of BCSA exhibits two intense and broad signals at 126 and 117 ppm attributed to polycyclic aromatic carbons [17,51]; this is different from the spectra of highly cross-linked BCSA materials $[17,51]$, which display only one symmetric peak at $130 \mathrm{ppm}$. In addition, the two broad signals at ca. 154 and $195 \mathrm{ppm}$ may be assigned to phenolic $\mathrm{OH}$ and $\mathrm{COOH}$ groups, respectively. The signals of the $\mathrm{OH}$ and especially $\mathrm{COOH}$ groups are split, implying that BCSA contains two kinds of polycyclic aromatic carbons with a different cross-linking degree or arrangement type, which leads to different environments surrounding its $\mathrm{OH}$ and especially $\mathrm{COOH}$ groups. In sharp contrast, the ${ }^{13} \mathrm{C}$ peak of the $\mathrm{SO}_{3} \mathrm{H}$ groups at $143 \mathrm{ppm}$ [31] is hardly noticeable for the parent BCSA, in agreement with previous reports $[17,51]$. No clear ${ }^{13} \mathrm{C}$ NMR signals for the $\mathrm{sp}^{3}$ carbons at $0-40 \mathrm{ppm}$ are observed in Fig. 3e, indicating that most of the $\mathrm{sp}^{3}$ carbons in the cellulose molecules of the bamboo material have been converted to the corresponding aromatic $\mathrm{sp}^{2}$ carbons after the hydrothermal carbonization treatment. The above-mentioned signals are not split in the ${ }^{13} \mathrm{C}$ NMR spectra of the two SIBCSA materials, but the signal of their polycyclic aromatic carbons shows a slight shift to low field (curves 2 and 3 in Fig. 3e), indicating that the silica-induced isolation results in the polycyclic aromatic carbons having uniform structure and chemical environment. In the solid-state ${ }^{29} \mathrm{Si}$ MAS NMR spectra of the two SIBCSA materials (Fig. 3f), the two peaks at around $104\left(\mathrm{Q}_{3}\right)$ and $114\left(\mathrm{Q}_{4}\right)$ ppm can be assigned to surface silanol groups, i.e., $\left[(\mathrm{SiO})_{3} \mathrm{Si}-\mathrm{OH}\right]$ and $\left[(\mathrm{SiO})_{4} \mathrm{Si}\right]$ units, respectively $[52,53]$.

The results of the above characterizations strongly suggest that SIBCSA-1, as a cheap solid acid, possesses high thermal stability and highly exposed superacid sites, as well as abundant mesoporous/macroporous channels with excellent mass transfer rate. Therefore, this novel acidic material is expected to show excellent performance in acid-catalyzed reactions. Three important typical acid-catalyzed reactions were then carried out to test the catalytic performance of SIBCSA-1, which was compared to those of the parent BCSA, control SIBCSA-2, and commercial Amberlyst-15 samples.

\subsection{Acid catalysis reactions}

The etherification of isobutylene with methanol is an important acid-catalyzed reaction used to produce the common gasoline additive MTBE. Table 2 shows a comparison of the data obtained for this reaction using the present solid acid catalysts in a batch reactor. SIBCSA- 1 exhibits the highest activity among the four solid catalysts, giving an $88.7 \%$ MTBE yield after reacting at $65{ }^{\circ} \mathrm{C}$ for $2 \mathrm{~h}$, along with a TOF up to $127 \mathrm{~h}^{-1}$, which is more than two times higher than those obtained with the two reference catalysts Amberlyst-15 and BCSA. However, the SIBCSA-2 sample only gives a MTBE yield of ca.14.0\% under the same conditions, owing to the severe self-polymerization of isobutylene in its micropores. Figure 4a shows the results obtained for the above reaction using SIBCSA-1 and the two reference catalysts under different reaction temperatures. The superior activity of SIBCSA-1 is further enhanced when the reaction temperature is reduced to 55 and especially $45^{\circ} \mathrm{C}$. For example, its TOF can still reach $87 \mathrm{~h}^{-1}$ at $45^{\circ} \mathrm{C}$, which is three and seven times higher than the corresponding values of BCSA and Amberlyst-15, respectively. This fully supports the suggestion that the superacidity of SIBCSA-1 can lead to an excellent low-temperature activity [54]. Figure $4 \mathrm{~b}$ further shows that SIBCSA- 1 can achieve a MTBE yield above $84 \%$ after being reused four times, and no dissolution of its SCNSs into the reaction solution occurs during the recycling runs (Fig. S6a). In sharp contrast, leaching of the catalyst in the reaction solution is observed in the recycling runs of Amberlyst-15 and especially BCSA, with a resulting obvious decrease in the MTBE yield of these two catalysts.

The hydrolysis of cellulose is another acid-catalyzed key reaction for the production of biomass-derived chemicals. The hydrolysis of hydroxypropyl cellulose in water was performed to test the catalytic performance of the present solid acids. As shown in Table 2, all four solid acids exhibit significant activities in this reaction, yielding reducing sugars (52\%-82\% yield) as the main products, along with a small amount of 5-hydroxymethylfurfural (HMF, 0.2\%-3.7\% yield). SIBCSA-1 exhibits a high catalytic activity, providing the highest (82.4\%) RSs yield among the solid acids. Moreover, its TOF increases to $6.56 \mathrm{~h}^{-1}$, which is 2- and 4-fold higher than the TOFs obtained using BCSA and Amberlyst-15, respectively. Notably, SIBCSA-2 shows a slightly higher TOF $\left(6.7 \mathrm{~h}^{-1}\right)$ than SIBCSA- 1 in this hydrolysis, which may due to its high proportion of macropores that facilitate the diffusion of the soluble macromolecular sub-

Table 2

Reaction data for the etherification of isobutylene with methanol and hydrolysis of hydroxypropyl cellulose over the three investigated sulfonic acid solids a

\begin{tabular}{|c|c|c|c|c|c|c|c|c|}
\hline \multirow{2}{*}{ Catalyst } & \multirow{2}{*}{$\begin{array}{c}\mathrm{SO}_{3} \mathrm{H} / \\
\left(\mathrm{mmol} \cdot \mathrm{g}^{-1}\right)\end{array}$} & \multicolumn{2}{|c|}{ Etherification } & \multicolumn{3}{|c|}{ Hydrolysis $^{\mathrm{b}}$} & \multicolumn{2}{|c|}{ Esterification $^{\mathrm{c}}$} \\
\hline & & MTBE yield/\% & $\mathrm{TOF} / \mathrm{h}^{-1}$ & $\mathrm{RSs} / \%$ & $\mathrm{HMF} / \%$ & $\mathrm{TOF} / \mathrm{h}^{-1}$ & DOA yield $/ \%$ & $\mathrm{TOF} / \mathrm{h}^{-1}$ \\
\hline SIBCSA-1 & 1.57 & 88.7 & 127.1 & 82.4 & 3.71 & 6.52 & 92.2 & 184.4 \\
\hline SIBCSA-2 & 1.19 & 14.0 & 26.5 & 63.9 & 1.46 & 6.70 & 79.9 & 159.8 \\
\hline BCSA & 3.46 & 62.1 & 40.4 & 58.5 & 2.49 & 2.13 & 76.2 & 152.4 \\
\hline Amberlyst-15 & 5.01 & 76.0 & 34.1 & 52.4 & 0.16 & 1.31 & 65.7 & 131.4 \\
\hline
\end{tabular}

${ }^{\mathrm{a}}$ Turnover frequency (TOF) was calculated based on the yield of products (mmol)/(catalyst amount $\times$ its $\mathrm{SO}_{3} \mathrm{H}$ density (mmol) $\times$ time (h)); ${ }^{b} \mathrm{RSs}$ and $\mathrm{HMF}$ indicated reducing sugars and 5-hydroxy-methylfurfural; ${ }^{\mathrm{c}} 0.5 \%$ catalyst (defined as $\left(\mathrm{SO}_{3} \mathrm{H}\right.$ amount(mmol)/adipic acid amount(mmol)) $\left.\times 100 \%\right)$ at $125{ }^{\circ} \mathrm{C}$ for 1 h. 

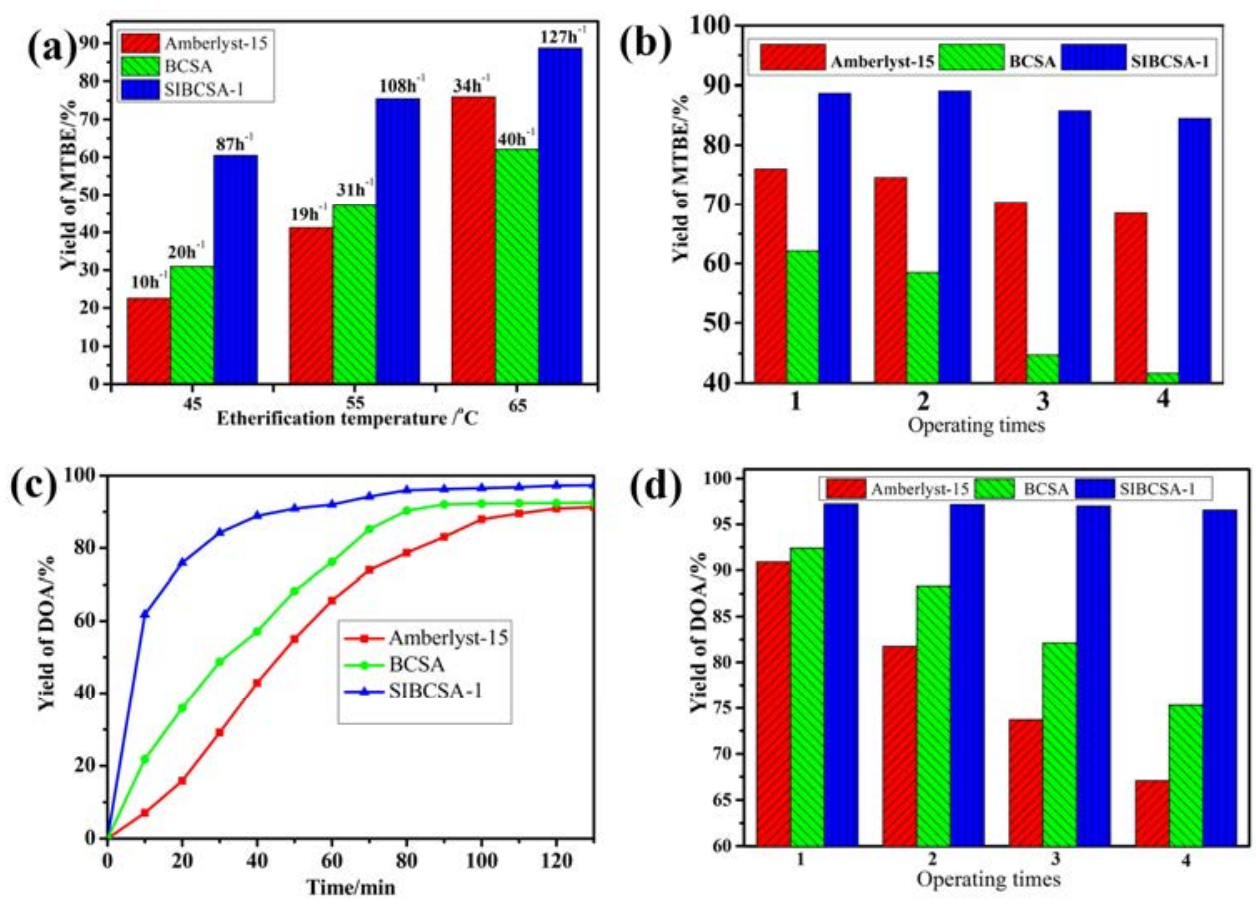

Fig. 4. Catalytic performance of the three solid acids. (a) Temperature dependence of MTBE yield (the corresponding TOF values are indicated above each bar) from etherification. (b) Repeatability of catalysts in esterification reaction. (c) Time-dependence of DOA yield from esterification. (d). Repeatability of catalysts in etherification reaction.

strate toward its strong acid sites. Moreover, the two SIBCSA catalysts show a good structural stability and their sulfonated SCNSs are hardly dissolved into the water medium even at a reaction temperature of $140{ }^{\circ} \mathrm{C}$ (Fig. S6b). On the contrary, Amberlyst-15 and especially BCSA are unstable under these hydrothermal reaction conditions, and exfoliation and dissolution of both structural units in water can occur, resulting in the two corresponding hydrolysis solutions showing an orange-yellow and orange color, respectively (Fig. S6b). Esterification of adipic acid with isooctanol can produce DOA, a good cold-resistant plasticizer that has been largely used in industry. As shown in Table 2, SIBCSA-1 exhibits an excellent activity, affording the highest TOF of $184.4 \mathrm{~h}^{-1}$ after $1 \mathrm{~h}$. Figure $4 \mathrm{c}$ further shows that SIBCSA- 1 exhibits a high catalytic rate in the early stages of esterification, and its DOA yield at $1 \mathrm{~h}$ increases up to $92.2 \%$, which is approximately equivalent to the yields obtained for the two reference catalysts at $2 \mathrm{~h}$. Fitting an irreversible second-order power model [55] to the esterification curves obtained using a low catalyst dosage $(0.2 \%)$ in Fig. S2 and Table S2 reveals that SIBCSA- 1 has a higher apparent rate constant $\left(0.0442 \mathrm{~L} \cdot \mathrm{mol}^{-1} \cdot \mathrm{min}^{-1}\right)$ than BCSA $(0.0376$ $\left.\mathrm{L} \cdot \mathrm{mol}^{-1} \cdot \mathrm{min}^{-1}\right)$ and especially Amberlyst-15 $\quad(0.0074$ $\mathrm{L} \cdot \mathrm{mol}^{-1} \cdot \mathrm{min}^{-1}$ ). The estimated apparent activation energy for the SIBCSA-1-catalyzed reaction at 125 and $115^{\circ} \mathrm{C}$ is $85 \mathrm{~kJ} / \mathrm{mol}$, which is slightly lower than that $\left(95 \mathrm{~kJ} \cdot \mathrm{mol}^{-1}\right)$ previously reported for the heteropoly acid-catalyzed homogeneous reaction [56]. Figure 4d further shows that SIBCSA-1 has superior repeatability compared to those of the two reference catalysts. The reaction catalyzed by the SIBCSA- 1 catalyst after four re- uses still produces a colorless DOA liquid with excellent yield (above 97\%). In contrast, after being reused four times, BCSA and Amberlyst-15 show a DOA yield loss of $7.1 \%$ and $9.8 \%$, respectively, and the color of the DOA liquid shown in Fig. S6c is light yellow (Amberlyst-15) or orange (BCSA).

In addition, the comparison of the data in Table $\mathrm{S} 3$ shows that SIBCSA- 1 has a much higher activity than $98 \% \mathrm{H}_{2} \mathrm{SO}_{4}$ in the three conversion reactions discussed above. The superior catalytic activity of SIBCSA-1 in these reactions is likely due to its abundant hierarchical pores, high external surface area, and highly exposed superacid sites, which accelerate the diffusion and conversion of reactants on its strong acid sites. Equally importantly, silica isolation imparts excellent structural stability to SIBCSA-1 via its chemical and hydrogen bonding interactions with the SCNSs: the FT-IR spectrum of SIBCSA-1 in Fig. S7 confirms the presence of such chemical bond interactions. In contrast, the two reference catalysts are deactivated to varying degrees in the recycling runs, due to their unstable structures. Notably, the data in Tables $\mathrm{S} 4-\mathrm{S} 6$ show that the $\mathrm{SO}_{3} \mathrm{H}$ groups of SIBCSA- 1 are not easily lost in the three conversions compared to those in the reference catalysts, due again to the strong hydrogen bonding interactions. In addition, the TGA results of the recovered catalysts after etherification (Figs. S8-S10 and Tables S4-S6) show that SIBCSA-1 exhibits outstanding advantages in reducing the deposition of isobutylene polymers (ca. 3 wt.\%) on its acid sites compared to those of Amberlyst-15 (as high as ca. 25 wt.\%). This is likely due to its hydrophilicity, and in particular to the unique role played by the adsorbed water on its surface in limiting the self-polymerization 


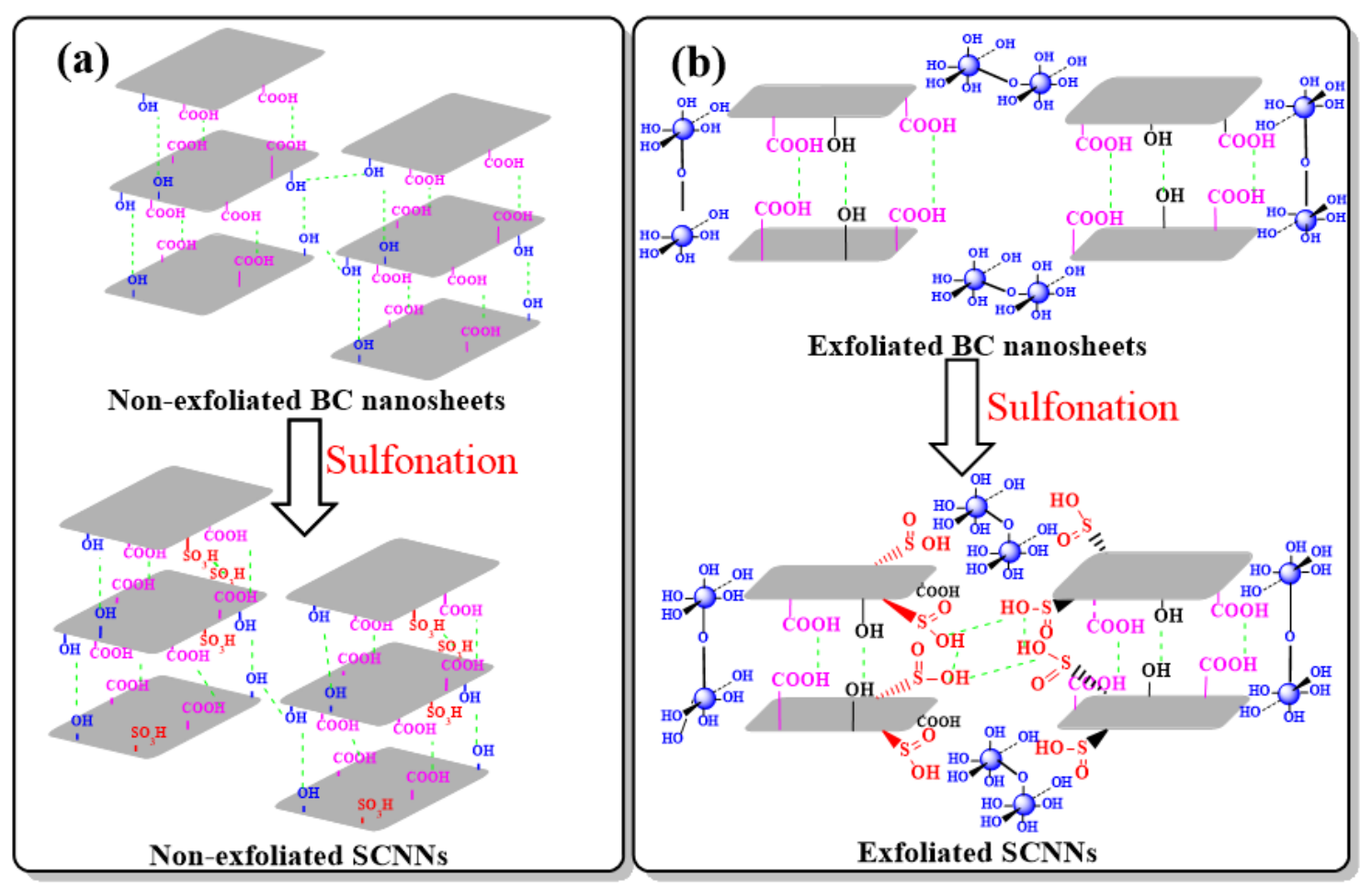

Fig. 5. Proposed formation process of hydrogen bond networks for the non-exfoliated (a) and exfoliated (b) BC nanosheets before and after sulfonation.

of isobutylene [57].

\subsection{Fabrication mechanism of biochar-based superacid}

The results of the above characterizations indicate that the non-exfoliated CNSs of the BC material spontaneously rearrange into a layered structure, mainly induced by the HB interactions among their weak acidic groups. These stable CNSs are unlikely to rearrange during their sulfonation, due to the restricting effect of their super hydrogen bonding networks (SHBNs). Therefore, the non-exfoliated SCNSs of BCSA hardly show superacidity, owing to the lack of strong hydrogen bonding interactions among their $\mathrm{SO}_{3} \mathrm{H}$ groups (Figure 5a). In contrast, the exfoliated CNSs of SIBC-1 may become partially mobile (owing to the breakage of their SHBNs) and undergo a specific rearrangement in the confined space of the silica surface hydroxyls during sulfonation (Fig. 5b). Such rearrangement, whose details are still unclear at present, is likely to induce the $\mathrm{SO}_{3} \mathrm{H}$ groups of SIBCSA- 1 to reconstruct the strong local hydrogen bonding network (LHBN) confined by the surface hydroxyls of silica by increasing their spatial proximity [30,45], thus leading to the generation of superacid sites over SIBCSA-1. It should be noted that if the highly isolated state of the CNSs is lost upon their re-aggregation under deep hydration at $350{ }^{\circ} \mathrm{C}$, the above $\mathrm{SO}_{3} \mathrm{H}$-dominated rearrangement will hardly occur, owing to their substantial cross-linking upon sulfonation. As a result, SIBCSA-2 (like BCSA) is not able to develop a LHBN among its $\mathrm{SO}_{3} \mathrm{H}$ groups, thus losing its superacidity.

\section{Conclusions}

A biomass carbon-derived solid superacid suitable for diverse acid-catalyzed reactions has been successfully fabricated by a silica isolation method. The catalyst exhibits the following advantages: 1) in addition to requiring very cheap and readily available raw materials, its fabrication involves simple and practical procedures, which are easy to implement in potential large-scale applications; 2) the catalyst overcomes the intrinsic drawbacks of biochar-derived solid sulfonic acids, as a result of its structural and chemical stabilities under hydrothermal or solvothermal reaction conditions; 3 ) its acidity is stronger than that of $100 \% \mathrm{H}_{2} \mathrm{SO}_{4}$; more importantly, its abundant meso- and macroporous channels, high external surface area, and highly exposed superacid sites enable its extensive application to the acid catalysis of substrates with different polarities and molecular sizes. The favorable properties of the present renewable solid superacid are expected to prompt further applications in other biorefinery and industrially important reactions.

\section{References}

[1] P. Anastas, N. Eghbali, Chem. Soc. Rev., 2010, 39, 301-312.

[2] K. Qian, A. Kumar, H. Zhang, D. Bellmer, R. Huhnke, Renew. Sustain. Energy Rev., 2015, 42, 1055-1064.

[3] P. Sudarsanam, R. Zhong, S. Van den Bosch, S. M. Coman, V. I. Parvulescu, B. F. Sels, Chem. Soc. Rev., 2018, 47, 8349-8402.

[4] Q. Wu, F. Liu, X. Yi, Y. Zou, L. Jiang, Green Chem., 2018, 20, 1020-1030.

[5] F. Liu, Q. Wu, C. Liu, C. Qi, K. Huang, A. Zheng, S. Dai, ChemSusChem, 2016, 9, 2496-2504.

[6] F. Liu, K. Huang, A. Zheng, F.S. Xiao, S. Dai, ACS Catal., 2018, 81, 372-391. 


\section{Graphical Abstract}

Chin. J. Catal., 2020, 41: 698-709 doi: S1872-2067(19)63522-9

Fabrication of a solid superacid with temperature-regulated silica-isolated biochar nanosheets

Zengtian Chen, Yuxue Xiao, Chao Zhang * , Zaihui Fu* , Ting Huang, Qingfeng Li, Yuanxiong Yao, Shutao Xu, Xiaoli Pan, Wenhao Luo, Changzhi Li*

Hunan Normal University; Dalian Institute of Chemical Physics, Chinese Academy of Sciences;

Dalian National Laboratory for Clean Energy, CAS

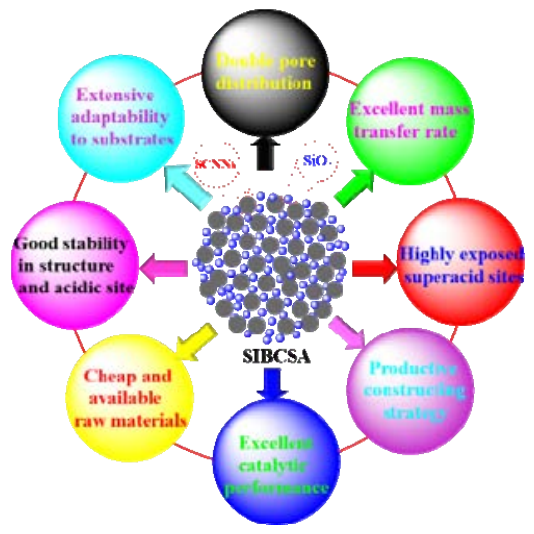

A newly fabricated silica-isolated biochar sulfonic acid exhibits abundant hierarchical pores along with stable and fully exposed superacid sites, thus showing significant advantages in acid catalysis reactions compared to those of common BCSA and commercial Amberlyst-15 catalysts.

[7] F. Liu, X. Yi, W. Chen, Z. Liu, W. Chen, C. Z. Qi, Y. F. Song, A. Zheng, Chem. Sci., 2019, 10, 5875-5883.

[8] J. Nie, J. Xie, H. Liu, J. Catal., 2013, 301, 83-91.

[9] S. Zhu, Y. Cen, J. Guo, J. Chai, J. Wang, W. Fan, Green Chem., 2016, 18, 5667-5675.

[10] S. Zhu, X. Gao, Y. Zhu, Y. Li, Green Chem., 2016, 18, 782-791.

[11] S. Zhu, Y. Xue, J. Guo, Y. Cen, J. Wang, W. Fan, ACS Catal., 2016, 6, 2035-2042.

[12] H. Xia, S. Xu, H. Hu, J. An, C. Li, RSC Adv., 2018, 8, 30875-30886.

[13] M. Toda, A. Takagaki, M. Okamura, J. N. Kondo, S. Hayashi, K. Domen, M. Hara, Nature, 2005, 438, 178.

[14] J. H. Clark, Green Chem., 2006, 8, 17-21.

[15] S. Suganuma, K. Nakajima, M. Kitano, D. Yamaguchi, H. Kato, S. Hayashi, M. Hara, J. Am. Chem. Soc., 2008, 130, 12787-12793.

[16] M. Okamura, A. Takagaki, M. Toda, J. N. Kondo, K. Domen, T. Tatsumi, M. Hara, S. Hayashi, Chem. Mater., 2006, 18, 3039-3045.

[17] K. Nakajima, M. Hara, ACS Catal., 2012, 2, 1296-1304.

[18] G. Chen, X. Wang, Y. Jiang, X. Mu, H. Liu, Catal. Today, 2019, 319, 25-30.

[19] C. Zhang, Z. Fu, Y. C. Liu, B. Dai, Y. Zou, X. Gong, Y. Wang, X. Deng, H. Wu, Q. Xu, K. R. Steven, D. Yin, Green Chem., 2012, 14, 1928-1934.

[20] Z. Yue, C. L. Mangun, J. Economy, Carbon, 2002, 40, 1181-1191.

[21] M. J. B. Evans, E. Halliop, J. A. F. MacDonald, Carbon, 1999, 37, 269-274.

[22] M. A. Lillo-Ródenas, D. Cazorla-Amorós, A. Linares-Solano, Carbon, 2003, 41, 267-275.

[23] M. Li, C. Yu, C. Hu, C. Zhao, M. Zhang, Y. Ding, X. Wang, J. Qiu, Green Chem., 2018, 20, 250-254.

[24] S. Jun, S. H. Joo, R. Ryoo, M. Kruk, M. Jaroniec, Z. Liu, T. Ohsuna, O. Terasaki, J. Am. Chem. Soc., 2000, 122, 10712-10713.
[25] H. Yang, D. Zhao, J. Mater. Chem., 2005, 15, 1217-1231.

[26] Z. Li, W. Yan, S. Dai, Carbon, 2004, 42, 767-770.

[27] L. Chengdu, H. Kunlun, D. Sheng, Angew. Chem. Int. Ed., 2004, 43, 5785-5789.

[28] F. Zhang, Y. Meng, D. Gu, Yan, C. Yu, B. Tu, D. Zhao, J. Am. Chem. Soc., 2005, 127, 13508-13509.

[29] R. Siegel, E. Domingues, R. De Sousa, F. Jerome, C. M. Morais, N. Bion, P. Ferreira, L. Mafra, J. Mater. Chem., 2012, 22, 7412-7419.

[30] I. K. Mbaraka, B. H. Shanks, J. Catal., 2006, 244, 78-85.

[31] X. Zhang, Y. Zhao, S. Xu, Y. Yang, J. Liu, Y. Wei, Q. Yang, Nat. Commun., 2014, 5, 3170.

[32] M. Brändle, J. Sauer, J. Am. Chem. Soc., 1998, 120, 1556-1570.

[33] J. P. Dacquin, H. E. Cross, D. R. Brown, T. Duren, J. J. Williams, A. F. Lee, K. Wilson, Green Chem., 2010, 12, 1383-1391.

[34] M. A. Harmer, W. E. Farneth, Q. Sun, J. Am. Chem. Soc., 1996, 118, 7708-7715.

[35] A. Takagaki, M. Sugisawa, D. Lu, J. N. Kondo, M. Hara, K. Domen, S. Hayashi, J. Am. Chem. Soc., 2003, 125, 5479-5485.

[36] J. Wang, W. Xu, J. Ren, X. Liu, G. Lu, Y. Wang, Green Chem., 2011, 13, 2678-2681.

[37] F. H. Richter, K. Pupovac, R. Palkovits, F. Schüth, ACS Catal., 2013, 3, 123-127.

[38] R. Xing, N. Liu, Y. Liu, H. Wu, Y. Jiang, L. Chen, M. Hu, P. Wu, Adv. Funct. Mater., 2007, 17, 2455-2461.

[39] D. Margolese, J. A. Melero, S. C. Christiansen, B. F. Chmelka, G. D. Stucky, Chem. Mater., 2000, 12, 2448-2459.

[40] C. Zhang, Z. Cheng, Z. Fu, Y. Liu, X. Yi, A. Zheng, S. R. Kirk, D. Yin, Cellulose, 2017, 24, 95-106.

[41] K. Paul G, M. R. Keenan, Microsc. Microanal., 2006, 12, 538-544.

[42] P. Chad M, L. N. Brewer, Microsc. Microanal., 2010, 16, 259-272. 
[43] P. F. Siril, H. E. Cross, D. R. Brown, J. Mol. Catal. A: Chem., 2008, 279, 63-68.

[44] P. Shen, M. Xu, D. Yin, S. Xie, C. Zhou, F. Li, Catal. Commun., 2016, 77 18-21.

[45] C. R. Costin, P. Jenkintown, US Patent, 4269943, 1981.

[46] B. Joachim Klein, B. Hartmut Widdecke, D. Frank, P. Fritz, US Patent, 4522952, 1985.

[47] J. C. Broekhoff, J. H. de Boer, J. Catal., 1967, 9, 8-14.

[48] M. S. Kim, D. Bhattacharjya, B. Fang, D. S. Yang, T. S. Bae, J. S. Yu, Langmuir, 2013, 29, 6754-6761.

[49] A. Zheng, S. Liu, F. Deng, Chem. Rev., 2017, 117, 12475-12531.

[50] Z. He, Y. Jiang, Y. Li, J. Zhu, H. Zhou, W. Meng, L. Wang, L. Dai, Carbon, 2018, 127, 297-304.

[51] K. Nakajima, M. Okamura, J. N. Kondo, K. Domen, T. Tatsumi, S.
Hayashi, M. Hara, Chem. Mater., 2009, 21, 186-193.

[52] X. Feng, G. E. Fryxell, L. Q. Wang, A. Y. Kim, J. Liu, K. M. Kemner, Science, 1997, 276, 923-926.

[53] M. Pursch, L. C. Sander, K. Albert, Anal. Chem., 1996, 68, 4107-4113.

[54] G. Zi, C. Jian-min, H. Wei-ming, T. Yi, Stud. Surf. Sci. Catal., 1994, 90, 507-518.

[55] M. B. Abdul Rahman, N. Chaibakhsh, M. Basri, A. B. Salleh, R. N. Z. R. Abdul Rahman, Appl. Biochem. Biotechnol., 2009, 158, 722-735.

[56] X. Luan, X. Sun, X. Shi, N. Wang, D. Jiang, Fine Chem., 2008, 25, $1232-1235$.

[57] M. L. Honkela, A. Root, M. Lindblad, A. O. I. Krause, Appl. Catal. A: Gen., 2005, 295, 216-223.

\title{
温度调控二氧化硅隔离生物质碳纳米片构建固体超强酸
}

\author{
陈增添 ${ }^{\mathrm{a}, \mathrm{b}}$, 肖钰雪 ${ }^{\mathrm{a}, \mathrm{b}}$, 张 超 ${ }^{\mathrm{a},}$, 伏再辉, ${ }^{\mathrm{a}, \#}$, 黄 婷 ${ }^{\mathrm{a}}$, 李庆锋 ${ }^{\mathrm{a}}$, 姚远雄 ${ }^{\mathrm{a}}$, 徐舒涛 ${ }^{\mathrm{b}}$, \\ 潘晓丽 $\mathrm{b}$, 罗文豪 ${ }^{\mathrm{b}}$, 李昌志, $, \mathrm{c}, \$$ \\ a 湖南师范大学石化新材料与资源精细利用国家地方联合工程实验室, \\ 化学生物学与中药分析教育部重点实验室, 湖南长沙 410081 \\ $\mathrm{b}$ 中国科学院大连化学物理研究所, 辽宁大连 116023 \\ c中国科学院洁净能源创新研究院, 辽宁大连 116023
}

摘要: 随着现代化学工业的发展, 能源短缺和环境污染成为当下所面临的两大严峻问题. 酸催化是化学工业中生产各种燃 料和化学品的关键转化技术之一, 发展基于固体酸的高效、环境友好催化转化技术在当代绿色化工领域中占有十分重要的 地位. 其中基于资源丰富和可再生的生物质衍生的固体碳磺酸(BCSAs)因其价廉易得、在一些重要的酸催化反应中显示出 比商业化磺酸树脂更优的性能而成为当前催化研究领域的热点之一. 然而, 传统的BCSAs存在不稳定的致密层状结构及 相对低的酸强度、酸位可接近性和传质效率等天然缺陷, 制约了这类价廉易得的固体酸在工业上的广泛应用. 本论文以综 合解决BCSAs的这些缺陷为目标, 开展其结构重组工程(SRE)策略研究. 该SRE策略使用廉价的竹粉和水玻璃为主要原料, 竹粉首先通过水热催化炭化法转化为层状生物质碳(BC), 然后将BC材料先后用十六烷基三甲基澳化铵化学剥离、酸性硅 溶胶插入、再脱水转化为二氧化硅隔离的碳纳米片, 最后用浓硫酸磺化生成硅胶隔离的生物质碳磺酸.

TEM、STEM-EDS、BET、TGA和TMPO吸附 ${ }^{31}$ P MAS NMR表征结果表明, 改变脱水温度可以调控硅胶隔离碳纳米片 与其纳米粒子堆积状态, 在 $250^{\circ} \mathrm{C}$ 脱水条件下获得了具有松散颗粒堆积结构的二氧化硅高度隔离且非交联的碳纳米片, 经 磺化引入的磺酸基具有明显增强的热稳定性(其热分解温度比BCSA的高出 $23^{\circ} \mathrm{C}$ )和强于 $100 \%$ 硫酸的超强酸性 $(90.4 \mathrm{ppm}$ ${ }^{31} \mathrm{P}$ 化学位移), 并构建了丰富的分级狭缝孔(外表面积达 $211 \mathrm{~m}^{2} / \mathrm{g}$, 呈双孔分布), 其驱动力主要来源于引入的磺酸基之间的 强氢键相互作用. 将构建的生物质固体超强酸应用于典型的酸催化已二酸与异辛醇酯化、异丁烯与甲醇醚化和羟丙基纤 维素水解反应中, 与普通生物质碳磺酸和商用Amberlyst-15相比, 其催化活性和稳定性(重复使用性)具有突出优势. 这归因 于生物质固体超强酸具有优异的结构稳定性、高度暴露的超强酸性位以及丰富的介孔-大孔双通道. 本文不仅为构建生物 碳基固体超强酸提供了一种新的结构重组策略, 而且克服了普通生物质碳磺酸在应用中存在结构稳定性差、酸强度和孔隙 率不理想的缺陷.

关键词: 生物质转化; 生物质碳磺酸; 二氧化硅隔离; 固体超强酸; 酸催化

收稿日期: 2019-10-26. 接受日期: 2019-11-23. 出版日期: 2020-04-05.

*通讯联系人. 电子信箱: chaozhang2006@126.com

\#通讯联系人. 电子信箱: fzhhnnu@126.com

通讯联系人. 电子信箱: licz@dicp.ac.cn

基金来源：国家自然科学基金(21690080，21676079，21546010，21690083，21878288); 中国科学院战略性先导科技专项 (XDB17020100); 湖南省自然科学基金(2018JJ3335); 湖南省高校创新平台开放基金(18K016); 中国科学院洁净能源创新研究院 合作基金(DNL180302).

本文的电子版全文由Elsevier出版社在ScienceDirect上出版(http://www.sciencedirect.com/science/journal/18722067). 